\title{
Biomechanical behavior of CAD/CAM cobalt- chromium and zirconia full-arch fixed prostheses
}

\author{
Thaís Barbin', Letícia Del Rio Silva', Daniele Valente Velôso' ${ }^{1}$, Guilherme Almeida Borges', \\ Anna Gabriella Camacho Presotto', Valentim Adelino Ricardo Barão ${ }^{1}$, Francisco Carlos Groppo ${ }^{2}$, \\ Marcelo Ferraz Mesquita ${ }^{1 *}$
}

${ }^{1}$ Department of Prosthodontics and Periodontology, Piracicaba Dental School, University of Campinas, Piracicaba, Brazil

${ }^{2}$ Department of Physiological Sciences, Piracicaba Dental School, University of Campinas, Piracicaba, Brazil

\begin{abstract}
PURPOSE. To verify the influence of computer-aided design/computer-aided manufacturing (CAD/CAM) implantsupported prostheses manufactured with cobalt-chromium ( $\mathrm{Co}-\mathrm{Cr}$ ) and zirconia ( $\mathrm{Zr}$ ), and whether ceramic application, spark erosion, and simulation of masticatory cycles modify biomechanical parameters (marginal fit, screw-loosening torque, and strain) on the implant-supported system. MATERIALS AND METHODS. Ten full-arch fixed frameworks were manufactured by a CAD/CAM milling system with Co- $\mathrm{Cr}$ and $\mathrm{Zr}$ ( $\mathrm{n}=5 / \mathrm{group}$ ). The marginal fit between the abutment and frameworks was measured as stated by single-screw test. Screw-loosening torque evaluated screw stability, and strain analysis was explored on the implant-supported system. All analyses were performed at 3 distinct times: after framework manufacturing; after ceramic application in both materials' frameworks; and after the spark erosion in Co-Cr frameworks. Afterward, stability analysis was re-evaluated after $10^{6}$ mechanical cycles $(2 \mathrm{~Hz} / 150-\mathrm{N})$ for both materials. Statistical analyses were performed by Kruskal-Wallis and Dunn tests $(\alpha=.05)$. RESULTS. No difference between the two materials was found for marginal fit, screwloosening torque, and strain after framework manufacturing $(P>.05)$. Ceramic application did not affect the variables $(P>$.05). Spark erosion optimized marginal fit and strain medians for Co-Cr frameworks $(P<.05)$. Screwloosening torque was significantly reduced by masticatory simulation $(P<.05)$ regardless of the framework materials. CONCLUSION. Co-Cr and Zr frameworks presented similar biomechanical behavior. Ceramic application had no effect on the biomechanical behavior of either material. Spark erosion was an effective technique to improve $\mathrm{Co}-\mathrm{Cr}$ biomechanical behavior on the implant-supported system. Screw-loosening torque was reduced for both materials after masticatory simulation. [J Adv Prosthodont 2020;12:329-37]
\end{abstract}

KEYWORDS: Computer-aided design/computer-aided manufacturing (CAD/CAM); Dental marginal adaptation; Dental stress analysis; Implant-supported dental prostheses; Spark erosion

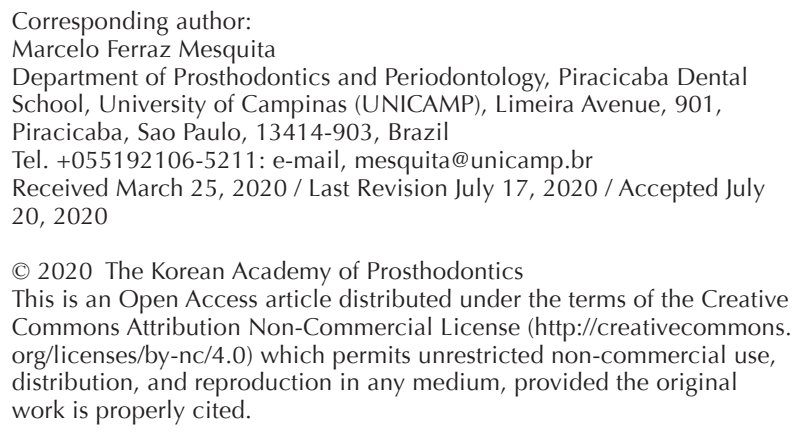

This study was supported by: the São Paulo Research Foundation (FAPESP, grants \#2017/15297-0 and \#2017/16303-3); the Coordenação de Aperfeiçoamento de Pessoal de Nível Superior - Brazil (CAPES, finance code \#001); and the Brazilian National Council for Scientific and Technological Development (CNPq), grant \#306373/2015-7.

\section{INTRODUCTION}

The choice of implant-supported fixed dental prostheses for complete edentulous arches has increased over the years. ${ }^{1-3}$ Anatomic curved arches can result in more manufacturing distortions, ${ }^{4,5}$ and a strict control of the prosthesis manufacturing process, including the attempt to achieve passive fit and greater stress distribution, has been encouraged in dental rehabilitation treatments. Therefore, biomechanical evaluation should be investigated, initially from the tightening of the prosthetic screw, in which the distribution of stress occurs in the implant supported component system. ${ }^{6,7}$

In attempts to achieve improved fit between framework and implant platforms, different manufacturing techniques 
have been developed, such as soldering, ${ }^{4}$ spark erosion, ${ }^{8}$ and elimination of laboratorial phases of the lost-wax technique through CAD/CAM milling technology. 'This technology, also classified as subtractive manufacturing, uses computer numerical control (CNC) machining with diamond burs that cut parts from a prefabricated block. ${ }^{10}$ This method is reported to promote results superior to those achieved by the lost-wax technique, ${ }^{10-12}$ by reducing some clinical and laboratory steps. ${ }^{13}$ Also, the technique can be conducted in materials such as titanium and its alloys, zirconia $(\mathrm{Zr})$ and cobalt-chromium alloys (Co-Cr) ${ }^{12,14} \mathrm{Co}-\mathrm{Cr}$ alloys have been recognized for their low cost, high elastic modulus, easy ceramic application, ease of casting, and the possibility of over-cast components, ${ }^{15}$ while $\mathrm{Zr}$ has joined this field due to the esthetic demands of patients and clinicians along with its superior strength and rigidity. ${ }^{2,16}$ In the short term, the failure rate associated with the use of $\mathrm{Zr}$ is very low. ${ }^{16}$ However, results regarding the marginal fit and stress distribution of Zr full-arch fixed dental prostheses (FAFDPs) are widely discussed, ${ }^{6,10,12,17,18}$ since corrective techniques cannot be applied in Zr frameworks.

Irrespective of the framework material, ceramic application has been proven to increase distortion in implant-supported prostheses. ${ }^{17,19,20}$ Some possible explanations are regarding material type, prostheses' size, ceramic firing cycles, and their temperature. ${ }^{17,20}$ In this context, laser welding and spark erosion are possible alternatives to improve the adaptation of the implant-supported system. ${ }^{8,20,21}$ Spark erosion preserves the original resistance of the prosthesis and its veneering porcelain coverage as it incorporates the refinement of the margin framework by electrical discharges, correcting adaptation without framework sectioning. ${ }^{8,20}$ However, the authors are unaware of studies in which spark erosion application has been used in CAD/CAM milling prostheses.

Beyond the attempt to achieve adequate marginal fit values, prosthetic screw-loosening is a current drawback in implant rehabilitation. ${ }^{22,23}$ In addition, external forces such as chewing accelerate the process of loosening torque, due to the movement of the sliding screw threads. The consequence is the presence of an instability that decreases the preload to a critical level. ${ }^{7,24}$ The effects of these external forces can be observed by a mechanical cycle device, which is used to simulate masticatory function. ${ }^{15,25} \mathrm{~A}$ previous study $^{25}$ reported that screw-retained zirconia FAFDPs supported by six implants presented higher torque loss when compared with titanium FAFDPs. However, the comparison with Co-Cr frameworks with four implants has not been previously evaluated.

Hence, this in vitro study aimed to investigate: (1) the effect of framework materials (Co-Cr and $\mathrm{Zr}$ ) on the biomechanical behavior of subtractive CAD/CAM FAFDPs (marginal fit, stability, and strain); (2) the influence of ceramic application on biomechanical behavior; (3) the effect of spark erosion on subtractive CAD/CAM FAFDP Co-Cr prostheses; and (4) screw-loosening stability after masticatory simulation. The null hypotheses were that (1) framework materials (Co-Cr and $\mathrm{Zr}$ ) would have no effect on the biomechanical behavior of subtractive CAD/CAM FAFDPs; (2) no differences in biomechanical behavior would be found after ceramic application for the two material; (3) spark erosion would not improve marginal fit, stability, and strain in Co-Cr prostheses; and (4) no differences would be found in the stability of either material after masticatory simulation.

\section{MATERIALS AND METHODS}

A fully edentulous maxillary replica (master model) was prototyped from the database of the Renato Archer Information Technology Center (Campinas, Sao Paulo, Brazil). ${ }^{26}$ All-onfour implant concept was used in the master model: 2 implants (Easy Grip Porous, $4.1 \times 11.5 \mathrm{~mm}$; Conexão Sistemas de Prótese Ltd., Aruja, Sao Paulo, Brazil) placed in the lateral incisor regions and 2 implants (Easy Grip Porous, $4.1 \times 13 \mathrm{~mm}$; Conexão - Sistemas de Prótese Ltd.) tilted distally at $30^{\circ}$ placed in the second premolar area. ${ }^{26}$ Microunit abutments (mini-abutment $4.1 \times 4.0 \mathrm{~mm}$; Conexão Sistemas de Prótese Ltd.) were screwed onto the anterior implants, and 30-degree-inclined mini-abutments (angled mini-abutment $4.1 \times 4.0 \mathrm{~mm}$; Conexão - Sistemas de Prótese Ltd.) were screwed onto the tilted implants. Twenty $\mathrm{Ncm}$ torque was applied in each of the four abutments (Torque Meter TQ-8800; Lutron, Taipei, Taiwan) and designated as abutments $\mathrm{A}, \mathrm{B}, \mathrm{C}$, and D (Fig. 1).

The study was divided into four phases: initial ( $1^{\text {st }}$ phase); ceramic application ( $2^{\text {nd }}$ phase $)$; spark erosion $\left(3^{\text {rd }}\right.$ phase); and masticatory simulation $\left(4^{\text {th }}\right.$ phase). Ten frameworks were manufactured by CAD/CAM milling system in $\mathrm{Co}-\mathrm{Cr}$ $(\mathrm{n}=5)$ and $\mathrm{Zr}(\mathrm{n}=5)$, simulating maxillary FAFDPs. The initial marginal fit, screw-loosening torque, and the strain induced on the implant analogs were analyzed ( $1^{\text {st }}$ phase). Ceramic application was conducted in all frameworks, and

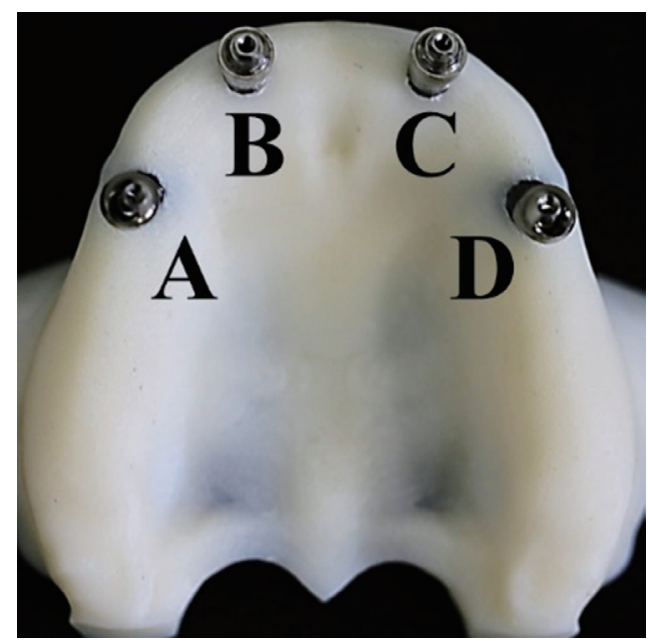

Fig. 1. Master model. 
the tests were repeated ( $2^{\text {nd }}$ phase). Spark erosion was performed in Co-Cr frameworks, followed by the repetition of the tests $\left(3^{\text {rd }}\right.$ phase). Masticatory simulation was conducted to evaluate screw-loosening torque in all frameworks $\left(4^{\text {th }}\right.$ phase) (Fig. 2).

A light scanner (Ceramill map 400+, Amann Girrbach, Koblach, Germany) scanned the master model with scan bodies (Scan Connect Micro-unit, Conexão - Sistemas de Prótese Ltd.) tightened on the abutments, and the framework's digital file was designed (Ceramill Mind software, Amann Girrbach). The specimens were obtained from $\mathrm{Co}-\mathrm{Cr}$ blocks (Starbond Easy Disc; Scheftner, Mainz, Germany) (61\% Co, 27.5\% Cr, 8.5\% W, 1.6\% Si, < 1\% C, < 1\% Mn, <
$1 \% \mathrm{Fe}$, and elastic modulus of $191 \mathrm{GPa})(\mathrm{n}=5)$ by a milling machine (CNC D15W; Yenadent, Istanbul, Turkey), as were the pre-sintered yttrium-stabilized tetragonal zirconia polycrystal blocks (ZirkOM SHT; Aidite (Qinhuangdao) Hightechnical Ceramics, Qinhuangdao, China) (94.39\% $\mathrm{ZrO}_{2}$, $5.3 \% \mathrm{Y}_{2} \mathrm{O}_{3}, 0.31 \%$ other oxides, and elastic modulus of 200 $\mathrm{GPa})$ (Ceramill Motion 2; Amann Girrbach) ( $\mathrm{n}=5$ ). Afterward, the Zr frameworks were finished in a sintering furnace (Ceramill Therm S; Amann Girrbach), at $1530^{\circ} \mathrm{C}$ for 12 hours, following the manufacturer's instructions. Thus, Co-Cr and Zr frameworks were obtained. The height of both frameworks was approximately $10 \mathrm{~mm}$ (Figs. 3A, 3B).

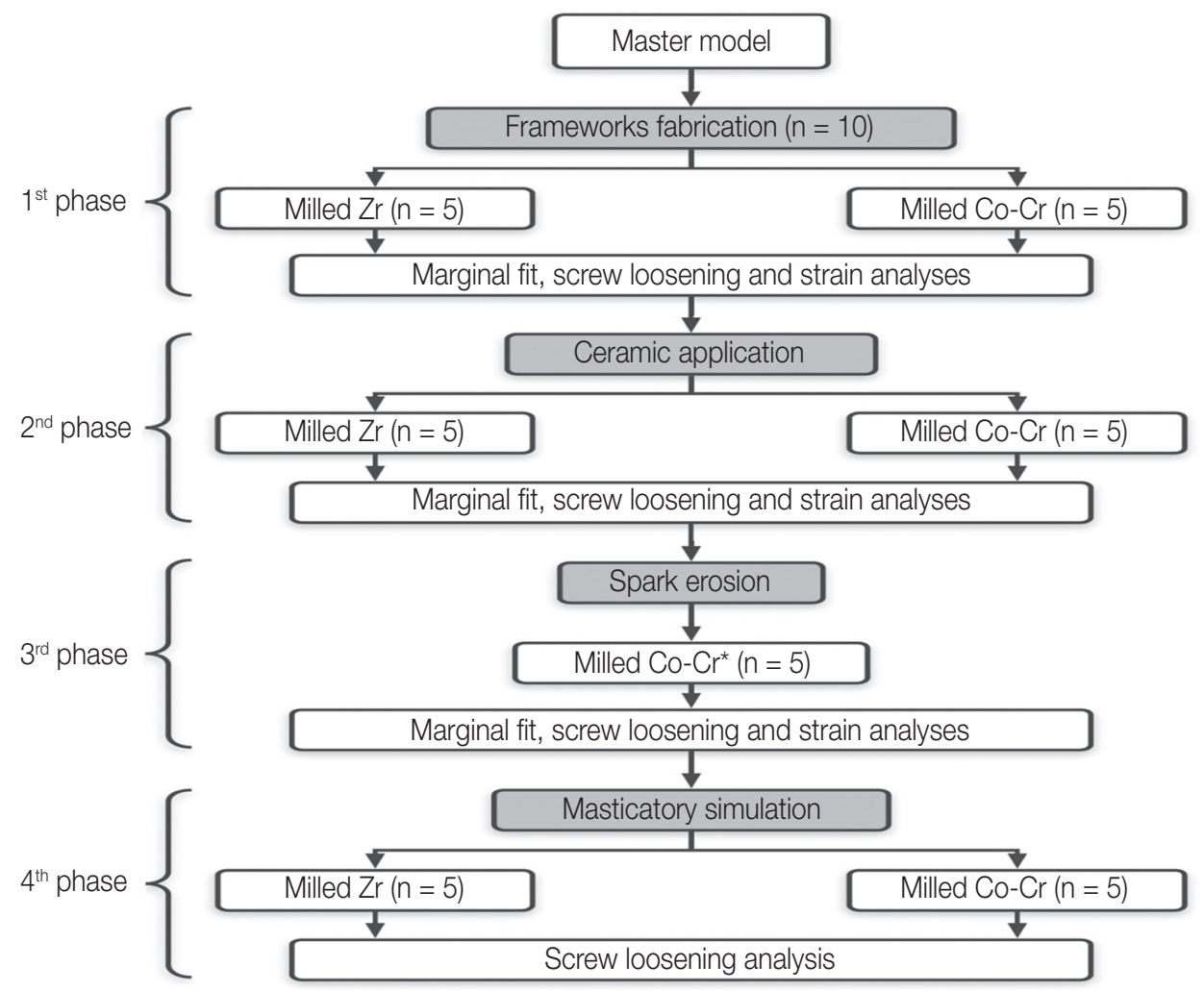

Fig. 2. Flowchart of study methodology design. $*$ Zr frameworks did not receive spark erosion, since it can only be conducted on metallic frameworks.

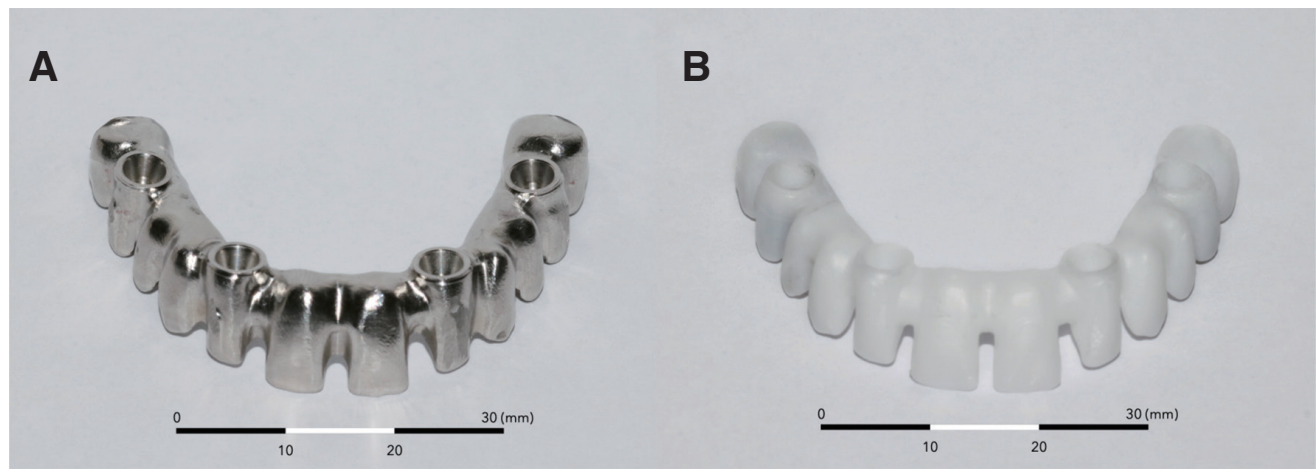

Fig. 3. Full-arch fixed dental framework from (A) Cobalt-Chromium, (B) Zirconia groups. The scale describes the size of the frameworks in width. 
The marginal fit values were obtained by the singlescrew test protocol. ${ }^{15,20,22,27}$ Each framework was settled on the master model, with the help of a digital torque meter (Torque Meter TQ-8800; Lutron), and the screw at one extremity (abutment A) received a $10-\mathrm{Ncm}$ torque. Values of all abutments (A, B, C, and D) at the framework/abutment interface were assessed on both buccal and lingual sides (in the mini-abutment platform center) (Fig. 4). The measurement was repeated with the abutment D tightened, resulting in 48 measurements to obtain a mean fit value for each framework. ${ }^{15,20,22,27}$ The examiner was previously calibrated (T.B.) (0.996 intra-class correlation coefficient, $P<$ 0.001) to perform the fit measurements, using a microscope at $120 \times$ magnification (VMM-100-BT; Walter UHL, Aßlar, Germany) associated with a digital camera (KC-512NT; Kodo Eletronics, Seoul, Korea) and a Quadra-check (QC 220-HH; Metronics Inc., Cincinnati, OH, USA).

The stability of the system was measured by screw-loosening torque in specific working models. Transfers were screwed on the master model and splinted with drills and low shrinkage self-curing acrylic resin (Pattern Resin LS, GC, Tokyo, Japan). The set was positioned into the silicone impression with the help of a parallelometer, after which the self-curing acrylic resin (Class Mold - Classico Artigos Odontológicos, Campo Limpo Paulista, Sao Paulo, Brazil) was poured. The framework was positioned on the working model, and each screw received a $10-\mathrm{Ncm}$ torque in A-DB-C sequence. ${ }^{15}$ Ten minutes later, the screws were retightened with $10-\mathrm{Ncm}$, and screw-loosening torque values were measured after 24 hours $^{23}$ (Torque Meter TQ-8800; Lutron). The average value was determined for each framework and each group. New screws were used for each framework in each study phase.

Strain-gauge analysis followed the methodology previously described. ${ }^{15,28}$ The mesial side of each modified conical implant abutment analog received one strain gauge (PA-

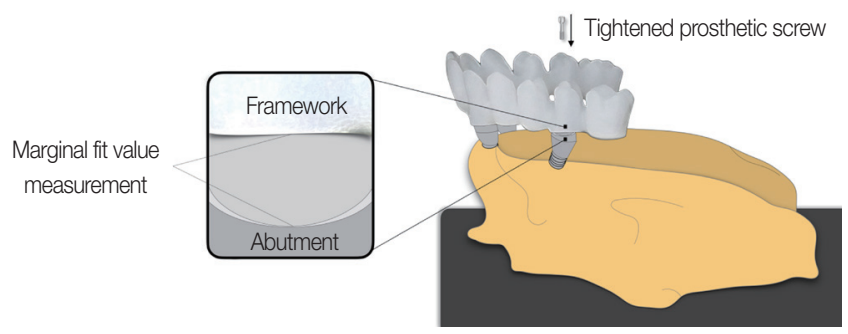

Fig. 4. Schematic representation of single-screw test. Prosthetic screw is tightened in the abutment located on the opposite side (abutment D). The marginal fit value measurement is obtained at the framework/abutment interface on buccal side (enlarged view on the left). Values of all abutments (A, B, C, and D) were assessed on both buccal and lingual sides.
06-060-BG-350 L; Excel Sensores Ltd., Taboao da Serra, Sao Paulo, Brazil), which was bonded with cyanoacrylatebased glue (Loctite Super Bonder; Henkel, Düsseldorf, Germany). ${ }^{15,28}$ This set was associated with a plaster type IV dental stone (Durone IV, Dentsply Sirona, York, PA, USA) manipulated following the manufacturer's recommendations. One-quarter Wheatstone bridge electric circuit was mounted with temperature control (Fig. 5). ${ }^{15,28}$ Then, each framework was settled in the modified analogs, the screws received a torque of $10-\mathrm{Ncm}$, similar to the same sequence described in the screw-loosening torque analysis, and the mean $\mu$ strain value was measured. ${ }^{15}$ After the torque of all screws, the $\mu$ strain was recorded for 10 minutes using a specific equipment (ADS 2000, Lynx Tecnologia Eletronica, Sao Paulo, Brazil), with data processing software (AqAnalysis 2000, Lynx Tecnologia Eletronica, Sao Paulo, Brazil). The strain gauges were reset between each new analysis to standardize the readings. ${ }^{6,15,28}$ The $\mu$ strain average value was determined for each framework and each group.

Ceramic application and related firings were conducted for all frameworks by an experienced dental technician according to manufacturer's recommendations (InSync $\mathrm{ZrO}_{2}$, Jensen Dental, North Haven, CT, USA for Zr frameworks; and feldspathic InSync MC, Jensen Dental, for Co-Cr frameworks) ( $2^{\text {nd }}$ phase). Co-Cr and $\mathrm{Zr}$ frameworks received five firing cycles in total (Table 1). Initially, a liner was applied to the $\mathrm{Zr}$ frameworks, followed by two dentin layers, one enamel layer to finalize the tooth shape, and glaze (Fig. 6). Co-Cr frameworks were initially sandblasted with $150 \mu \mathrm{m} \mathrm{Al}_{2} \mathrm{O}_{3}$ particles (Wilson, Polidental, Cotia, Sao Paulo, Brazil) at pressure of 3 bars and distance of up to 5 $\mathrm{cm}$. Residual $\mathrm{Al}_{2} \mathrm{O}_{3}$ particles were removed from the frameworks with water. Two opaque porcelain layers, followed by one dentin layer, one enamel layer, and glaze, were applied.

Spark erosion ( $3^{\text {rd }}$ phase) followed the methodology previously described. ${ }^{8,20}$ The procedure could be conducted

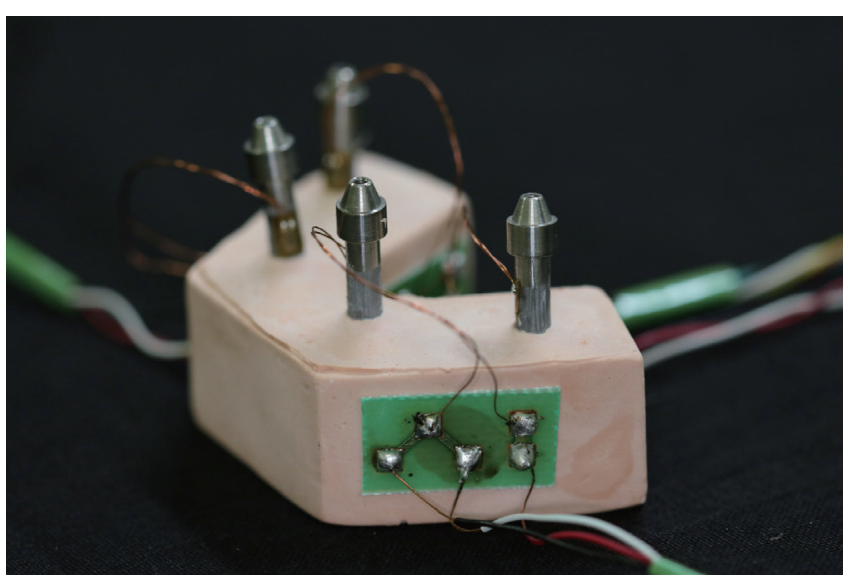

Fig. 5. Electric circuit in 1/4 Wheatstone bridge at straingauge model. 
Table 1. Firing cycles and heat rate for cobalt-chromium (Co-Cr) and zirconia ( $\mathrm{Zr}$ ) frameworks according to the manufacturers' recommendations

\begin{tabular}{|c|c|c|c|c|}
\hline Procedure & $\begin{array}{c}\text { Co-Cr } \\
\text { Firing temperature } \\
\text { (Initial - End) }\left({ }^{\circ} \mathrm{C}\right)\end{array}$ & $\begin{array}{c}\mathrm{Co}-\mathrm{Cr} \\
\text { Heat rate } \\
\left({ }^{\circ} \mathrm{C} / \mathrm{min}\right)\end{array}$ & $\begin{array}{c}\mathrm{Zr} \\
\text { Firing temperature } \\
\text { (Initial - End }\left({ }^{\circ} \mathrm{C}\right)\end{array}$ & $\begin{array}{c}\mathrm{Zr} \\
\text { Heat rate } \\
\left({ }^{\circ} \mathrm{C} / \mathrm{min}\right)\end{array}$ \\
\hline Liner & - & - & $400-970$ & 60 \\
\hline $1^{\text {st }}$ opaque layer & $450-950$ & 80 & - & - \\
\hline $2^{\text {nd }}$ opaque layer & $450-950$ & 80 & - & - \\
\hline $1^{\text {st }}$ dentin layer & $450-880$ & 60 & $400-765$ & 40 \\
\hline $2^{\text {nd }}$ dentin layer & - & - & $400-760$ & 40 \\
\hline $1^{\text {st }}$ enamel layer & $450-800$ & 60 & $400-700$ & 45 \\
\hline Glaze & $450-780$ & 50 & $400-730$ & 45 \\
\hline
\end{tabular}

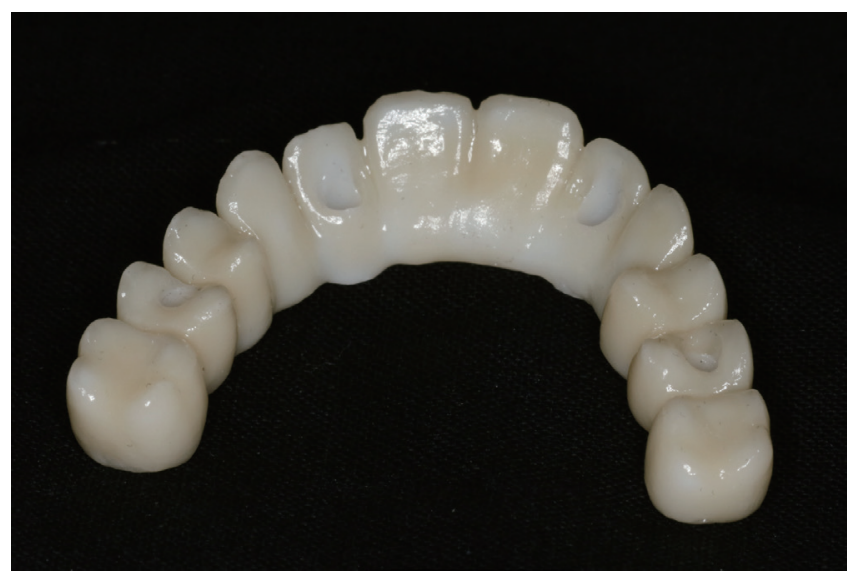

Fig. 6. Zirconia framework with ceramic application.

only for Co-Cr frameworks because of their electrical conductivity. The framework was placed in the spark erosion model and low shrinkage self-curing acrylic resin increments (Pattern Resin LS, GC, Tokyo, Japan) were used to connect the framework to the machine (Form 2-LC ZNC, Charmilles Technologies, Geneva, Switzerland). The model and framework were surrounded by dielectric fluid (Eletron, Archem Quimica Ltda, Araras, Sao Paulo, Brazil). The amperage used started with $3 \mathrm{~A}$, and finished with $1 \mathrm{~A}$. The vertical movement of the equipment shaft was controlled and uniform to those of all Co-Cr frameworks.

For the $4^{\text {th }}$ phase (masticatory simulation), $\mathrm{Co}-\mathrm{Cr}$ and $\mathrm{Zr}$ frameworks were placed in their respective working models. New screws were used with $10-\mathrm{Ncm}$ torque tightening, by means of a digital torque meter (Torque Meter TQ-8800; Lutron). These new screws received the same retightening protocol previously described for the stability analysis. One million $\left(10^{6}\right)$ mechanical cycles ${ }^{29}$ (Mechanical Fatigue Simulator ER11000 Plus, ERIOS, São Paulo, Brazil) were applied to all prostheses, with $2 \mathrm{~Hz}$ frequency, ${ }^{30}$ a $150 \mathrm{~N}^{23}$ oblique (30 degree angle $)^{30}$ load, directed on the right first molar occlusal surface. Artificial saliva at $37^{\circ} \mathrm{C}(1.5 \mathrm{mM} \mathrm{Ca}$, $3.0 \mathrm{mM} \mathrm{P}, 20.0 \mathrm{mM} \mathrm{NaHCO}_{3}$, $\mathrm{pH}$ 7.0) was used to immerse the prostheses. ${ }^{15}$

A priori sample size calculation was performed using data from Presotto et al. (2018). ${ }^{8}$ Considering a minimum difference to be detected of $10 \mu \mathrm{m}$ with a standard deviation of $2 \mu \mathrm{m}(20 \%)$ in the variable "marginal fit", five frameworks per group would provide $95 \%$ power with a $5 \%$ significance level. All variables were analyzed using the D'Agostino and Pearson test to verify normality and the Brown-Forsythe and Bartlett's tests to determine the homoscedasticity of their variances. Kruskal-Wallis and Dunn tests evaluated the influence of the material (Co-Cr and $\mathrm{Zr}$ ) and time (initial, ceramic application and spark erosion) on the marginal fit and strain values. On the screwloosening torque values, evaluation time was analyzed at initial, ceramic application, spark erosion, and masticatory simulation times. All data were presented as the median and interquartile range (IQR). GraphPad Prism 8.0 software (GraphPad Software Inc., San Diego, CA, USA) was used for statistical analysis, and the significance level was set at $5 \%$.

\section{RESULTS}

Marginal fit medians and IQR values are presented in Figure 7. Marginal fit median of Co-Cr frameworks after spark erosion (median 49.25, IQR 37.88 - $67.38 \mu \mathrm{m}$ ) was significantly lower than initial $\mathrm{Zr}$ (149.1, IQR 37.78 - $229.9 \mu \mathrm{m}$ ), ceramic veneered $\mathrm{Zr}(148.1$, IQR 72.94 - $305.5 \mu \mathrm{m})$, initial Co-Cr $(97.38$, IQR $39.0-193.8 \mu \mathrm{m})$ and ceramic veneered Co-Cr (189.6, IQR $42.34-226.3 \mu \mathrm{m})$ medians (KruskalWallis, $\mathrm{H}=26.91$; $\mathrm{df}=4, P<.0001)$. Marginal fit medians between the $\mathrm{Zr}$ and $\mathrm{Co}-\mathrm{Cr}$ at initial and ceramic veneered times were not significantly different $(P>.05)$.

Screw loosening torque medians and IQR values are presented in Figure 8. Screw-loosening median of $\mathrm{Co}-\mathrm{Cr}$ and $\mathrm{Zr}$ frameworks after mechanical cycling (Co-Cr median 
7.1, IQR 6.4 - 7.8 and Zr median 6.5, IQR 6.1 - 6.9 Ncm) was significantly lower than those of ceramic veneered $\mathrm{Zr}$ (8.0, IQR 7.1 - 8.5 Ncm) and spark eroded Co-Cr (8.1, IQR 6.9-9.5 Ncm) medians (Kruskal-Wallis, $\mathrm{H}=21.31$; $\mathrm{df}=4, P$ $=.0016)$. There were no differences in screw-loosening torque between the $\mathrm{Zr}$ and $\mathrm{Co}-\mathrm{Cr}$ at initial, ceramic veneered and mechanical cycled times $(P>.05)$.

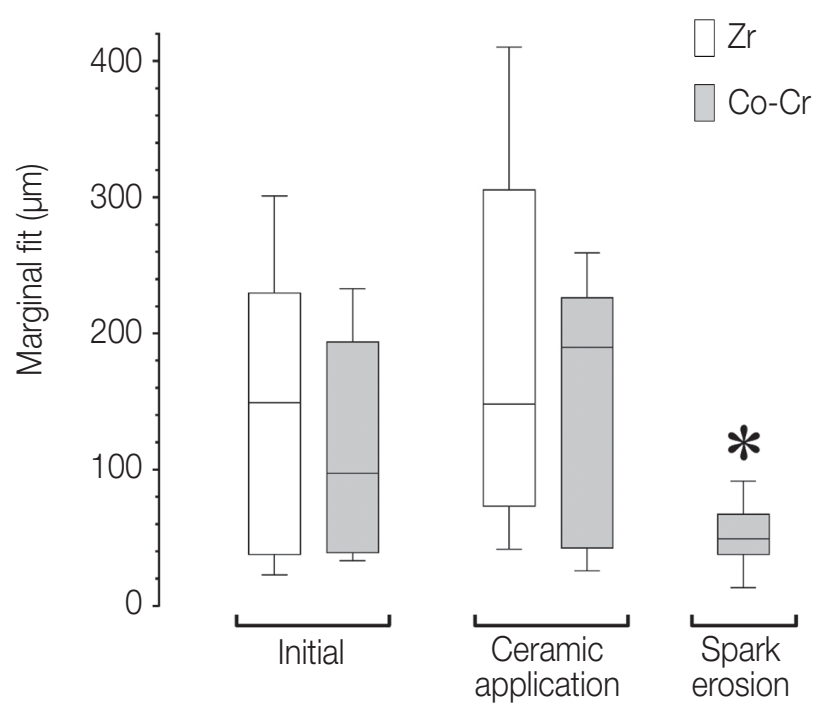

Fig. 7. Levels of marginal fit $(\mu \mathrm{m})$ for $\mathrm{Zr}$ and $\mathrm{Co}-\mathrm{Cr}$ groups at each evaluation time. Central bar = median value; boxes $=$ first and third quartiles; whiskers $=$ maximum and minimum values. *Significant difference between spark erosion $\mathrm{Co}-\mathrm{Cr}$ group and the initial $\mathrm{Zr}$, ceramic veneered $\mathrm{Zr}$, initial $\mathrm{Co}-\mathrm{Cr}$ and ceramic veneered $\mathrm{Co}-\mathrm{Cr}(P$ $<.05)$.

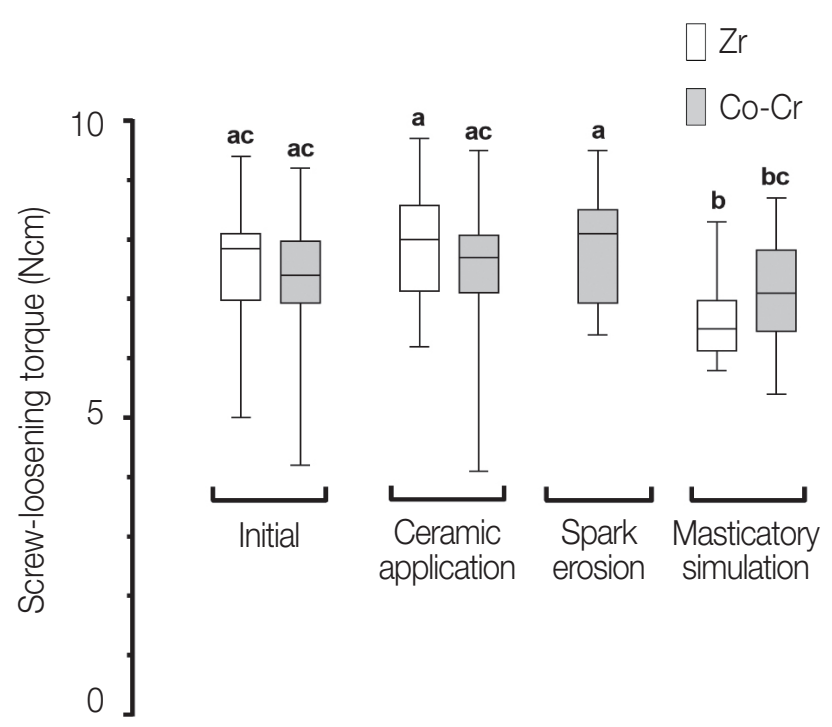

Fig. 8. Levels of screw-loosening torque $(\mathrm{Ncm})$ for $\mathrm{Zr}$ and $\mathrm{Co}-\mathrm{Cr}$ groups at each evaluation time. Central bar $=$ median value; boxes = first and third quartiles; whiskers = maximum and minimum values. Different lowercase superscript letters indicate statistically significant differences between the materials and evaluation time $(P<.05)$.
Strain medians and IQR values are presented in Figure 9. Strain median of Co-Cr frameworks after spark erosion (median 53.77, IQR 17.68 - $159.8 \mu$ strain) was significantly lower than initial $\mathrm{Zr}$ (311.6, IQR 147.8 - $706.2 \mu$ train), ceramic veneered $\mathrm{Zr}$ (306.7, IQR 95.41 - $538.7 \mu$ strain), initial Co-Cr (310.1, IQR 115.2 - $458.5 \mu$ strain) and ceramic veneered Co-Cr (267.7, IQR 114.0 - $418.8 \mu$ strain) medians (Kruskal-Wallis, $\mathrm{H}=23.86$; df $=4, P<.0001$ ). There were no differences in strain between the initial $\mathrm{Zr}$ and ceramic veneered $\mathrm{Zr}(P=.43)$, between initial $\mathrm{Co}-\mathrm{Cr}$ and ceramic veneered $\mathrm{Co}-\mathrm{Cr}(P=.99)$, between initial $\mathrm{Zr}$ and initial $\mathrm{Co}-\mathrm{Cr}(P=.32)$, and between ceramic veneered $\mathrm{Zr}$ and ceramic veneered $\mathrm{Co}-\mathrm{Cr}(P=.84)$.

\section{DISCUSSION}

The comparison between materials for a consolidated technology such as subtractive CAD/CAM manufacturing should not be neglected. CNC technology has been recognized as a reliable technique for $\mathrm{Co}-\mathrm{Cr}^{11}$ and $\mathrm{Zr}^{10}$ framework manufacturing, and once no statistically significant differences were found in aspects of the biomechanical behavior, the first null hypothesis - material frameworks would have no effect on the biomechanical behavior of subtractive CAD/CAM FAFDPs - was accepted.

Material influence was not observed for marginal fit, stability, and strain-gauge analyses. The discussion about passive fit centers around values up to $150 \mu \mathrm{m},{ }^{22}$ and up to 230 $\mu \mathrm{m}$ between the implants and framework; ${ }^{3}$ therefore, at the initial time the values found can be considered within the

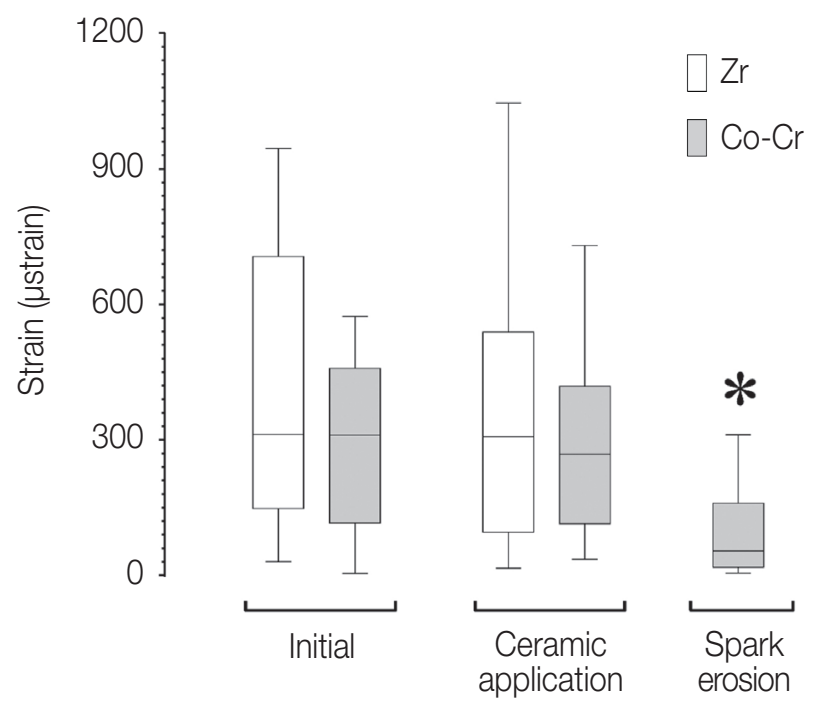

Fig. 9. Levels of strain ( $\mu$ strain) for $\mathrm{Zr}$ and Co-Cr groups at each evaluation time. Central bar = median value; boxes = first and third quartiles; whiskers = maximum and minimum values. *Significant difference between spark erosion Co-Cr group and the initial $\mathrm{Zr}$, ceramic veneered $\mathrm{Zr}$, initial $\mathrm{Co}-\mathrm{Cr}$ and ceramic veneered $\mathrm{Co}-\mathrm{Cr}(P<.05)$. 
clinically acceptable. A study with 3-unit, implant-supported, screw-retained frameworks also found no marginal fit statistical difference between materials. ${ }^{12}$ Although elasticity modulus of $\mathrm{Zr}$ is higher than that of $\mathrm{Co}-\mathrm{Cr}$, the milling process was conducted in a soft block of $\mathrm{Zr}$ in which the wear of burs does not occur on a large scale. ${ }^{5,31}$ The use of a high-speed 5-axis machine is reported to be able to reduce errors during milling, ensuring finishing and polishing procedures. ${ }^{13,32}$ A wasted bur or a non-calibrated machine could contribute to less accurate milling. ${ }^{32}$ Another factor that could influence marginal fit is the sintering process, mandatory when milling in soft blocks of $\mathrm{Zr}$. This $\mathrm{Zr}$ post-treatment is associated with $20-25 \%$ of the material shrinkage, ${ }^{14}$ and could induce uncontrolled distortions. ${ }^{17}$ The use of $\mathrm{Zr}$ frameworks for long-term prostheses should still be indicated with caution, because neither soldering nor spark erosion can be performed to improve biomechanical behavior; however, promising results were found as no difference in marginal fit, stability, and strain was noted between the two materials. Studies ${ }^{18,27}$ with smaller frameworks described a relationship in which lower fit could result in higher stress/strain in the implant-supported system rather than the material type, corroborating our findings. In a finite element analysis (FEA) study, ${ }^{26}$ stiffer materials such as Co-Cr and $\mathrm{Zr}$ supported by four implants did not exceed the bone resistance limit; thus the median strain values found in this study might not interfere with osseointegration, since bone is reported to have a remodeling process. ${ }^{15,33}$ Regarding stability, the protocol applied was described to be effective with casted $\mathrm{Co}-\mathrm{Cr},{ }^{23}$ and the results of this study confirmed it to be effective with milled CAD/CAM frameworks, irrespective of whether the material was $\mathrm{Zr}$ or $\mathrm{Co}-\mathrm{Cr}$.

The importance of ceramic application is related to the need for esthetics in $\mathrm{Co}-\mathrm{Cr}$ frameworks and protection for $\mathrm{Zr}$ frameworks, since the literature describes low-temperature aging as a complication during function. ${ }^{34}$ Positive results have been found after ceramic application for both materials, leading to acceptance of the second hypothesis, since no differences in biomechanical behavior were found after ceramic application for both materials. In a previous study, ${ }^{35}$ milled Zr frameworks supported by six implants were porcelain-veneered through three firing cycles, and no influence on the fit was found. The findings of this study added that ceramic application did not alter the values of marginal fit, screw-loosening torque and strain from the initial phase, even when five firing cycles were conducted. Thus, CNC technology is suitable for manufacturing consistent frameworks, reducing the chances of distortions being induced after veneering coverage.

One alternative to reduce distortions in prostheses is spark erosion. To the best of the authors' understanding, no study was found evaluating this option in Co-Cr full-arch implant-supported prostheses manufactured by CAD/CAM milling technology. Since one of the principles of CAD/ CAM is the manufacture of frameworks without the need for sectioning and soldering, the use of this fit-corrective technique for metallic frameworks would preserve the pros- thesis integrity and its ceramic veneering., ${ }^{8,20}$ The literature describes ceramic veneering as being responsible for inducing distortions in the frameworks. ${ }^{8,17,19,20}$ In this study, fortunately, ceramic application did not influence the biomechanical behavior of the frameworks, but the importance of spark erosion evaluation was to clarify whether prostheses manufactured by subtractive CAD/CAM systems could be improved. Spark erosion has been described as effective for prostheses with poor fit values, such as those fabricated by conventional casting. ${ }^{8,20}$ However, maintaining the clinical relevance, it is important to know that if a Co-Cr milled framework presents lower levels of fit, it can be improved by using spark erosion, without the need to manufacture a new framework, which would increase treatment costs and time. This thought can be extended to ceramic application. Different veneering materials, firing cycles, machines and technician ability might promote distortions that could be decreased without a new prostheses manufacturing. Therefore, the third hypothesis - spark erosion would not improve fit, stability, and stress distribution in Co-Cr subtractive CAD/ CAM prostheses - was rejected, since higher levels of fit and lower values of strain were found. Although screw stability was not significantly increased after spark erosion, it was not reduced.

The evaluation of titanium prosthetic screw-loosening for each framework manufacturing material was conducted because lower marginal fit between framework and abutment and external forces could influence and hinder preload maintenance. ${ }^{7}$ The screw-loosening process is a customary event in implant therapy, ${ }^{23,25}$ albeit it has been reported as preceding other severe mechanical and biological drawbacks, ${ }^{36}$ decreasing the longevity of the prosthesis. The tightening protocol aimed to prevent the partial loss of torque, ${ }^{23}$ which occurs regardless of external forces, mainly in the first minutes after screw-tightening. ${ }^{37}$ However, the fourth hypothesis - that no difference would be found between the stability of either material after masticatory simulation - was rejected. Adequate median values for screw-loosening torque were found at all times, ${ }^{23}$ but the main difference found was between the last phase of the study (masticatory simulation) and previous evaluation times. One million mechanical cycles were conducted based on results from earlier studies, ${ }^{15,29}$ and our results are in compliance with those of another study, ${ }^{25}$ which also attributed the lower screw-loosening values of $\mathrm{Zr}$ frameworks to screw deformation after fatigue testing and to slight thread changes, exacerbated when in contact with material of higher elastic modulus, such as $\mathrm{Zr}$, and joint vibration, which can reduce the preload. Nevertheless, it is important to state that even with significant screw-loosening values, regardless of the framework materials, none of the samples were visually apparently screw-loosened, which could indicate that the final preload in the screws may stand for a year of function. ${ }^{25}$ Ceramic chipping, which has been reported as one of the main technical complications of Zr-based prostheses, ${ }^{38}$ was also not shown. The effect of mechanical loading in milling CAD/CAM FAFDPs may be confirmed by further studies 
with different masticatory simulation times.

It is agreed that $\mathrm{Co}-\mathrm{Cr}$ and $\mathrm{Zr}$ are considered stiffer materials when compared with other materials used to manufacture dental frameworks, such as titanium and its alloys. According to the results found and previous literature, ${ }^{2,16,38}$ it is possible to suppose that both stiffer materials may be suitable for manufacturing extensive prostheses in clinical practice, as the CAD/CAM milling technology enables the fabrication of better fitting frameworks that are resistant to distortions. Stress evaluation on the frameworks and bone region was conducted in a previous FEA study, ${ }^{26}$ which corroborates our findings. The authors tested $\mathrm{Co}-\mathrm{Cr}$, $\mathrm{Zr}$, and titanium materials as implant-supported frameworks on a simulated maxilla bone region. They found higher stress levels in $\mathrm{Co}-\mathrm{Cr}$ and $\mathrm{Zr}$ frameworks than in titanium frameworks, and also found that both stiffer materials transmitted less stress levels for implants, screws, abutments, and cortical bone. ${ }^{26}$ Under acceptable fit conditions, materials such as $\mathrm{Co}-\mathrm{Cr}$ and $\mathrm{Zr}$ are more resistant to the bending moment during masticatory forces, and the stress distribution to the implant-supported system is mitigated and better distributed. On the other hand, a stiffer material associated with an unsatisfactorily fitted prosthesis may cause complications such as screw-loosening, catastrophic chipping and/or bone reabsorption more quickly than expected. The FEA study ${ }^{26}$ did not simulate ceramic coverage, which was evaluated in our study. The association of the results between our study, this previous FEA study, and literature would seem to support the reliable and adequate biomechanical behavior of stiffer materials for FAFDPs.

Each phase of this study was evidence-based dentistry. However, limitations can be related to the use of only one screw during fit measurements, which could decrease the fit values in the non-tightened abutments and mask the real situation; the use of work models for screw-loosening analysis, instead of the master model; and the measurement of strain only where the strain gauge was bonded, although it was to avoid a bias of bond in different positions in each framework. ${ }^{15}$

Overall, biomechanical studies play an important role in the literature. Through their initial in vitro view, the development and improvement of materials and technologies can be conducted. The esthetic characteristics of $\mathrm{Co}-\mathrm{Cr}$ are in contrast to its low cost and reduced hands-on requirement for dental technicians. On the other hand, $\mathrm{Zr}$ has superior esthetic characteristics in contrast to its chipping and degradation at low temperatures. Future research comparing FAFDPs with other materials such as titanium alloys, 3D printing CAD/CAM systems, more implants supporting rehabilitation such as the all-on-six concept, ${ }^{26}$ and longitudinal follow-ups of prostheses fabricated with these materials are necessary and could clarify the applicability of the findings of this study.

\section{CONCLUSION}

Milled Zr maxillary FAFDPs presented similar biomechani- cal behavior when compared with milled Co-Cr maxillary FAFDPs. Ceramic application did not affect the biomechanical behavior of $\mathrm{Zr}$ and Co-Cr FAFDPs supported by four implants. Spark erosion represented an effective technique to optimize the biomechanical behavior of milled $\mathrm{Co}-\mathrm{Cr}$ FAFDPs. One year of masticatory simulation can reduce the prosthetic screw-loosening torque of milled $\mathrm{Zr}$ and $\mathrm{Co}-\mathrm{Cr}$ prostheses supported by the all-on-four implant concept.

\section{ORCID}

Thaís Barbin https://orcid.org/0000-0001-5113-7312

Letícia Del Rio Silva https://orcid.org/0000-0002-1158-9960

Daniele Valente Velôso https://orcid.org/0000-0002-8607-1381

Guilherme Almeida Borges https://orcid.org/0000-0003-4724-9834

Anna Gabriella Camacho Presotto bttps://orcid.org/0000-00033330-0571

Valentim Adelino Ricardo Barão bttps://orcid.org/0000-0002-63919917

Francisco Carlos Groppo https://orcid.org/0000-0002-8513-773X

Marcelo Ferraz Mesquita bttps://orcid.org/0000-0003-1967-6628

\section{REFERENCES}

1. Papaspyridakos P, Bordin TB, Natto ZS, Kim YJ, El-Rafie K, Tsigarida A, Chochlidakis K, Weber HP. Double full-arch fixed implant-supported prostheses: Outcomes and complications after a mean follow-up of 5 years. J Prosthodont 2019; 28:387-97.

2. Rojas Vizcaya F. Retrospective 2- to 7-year follow-up study of 20 double full-arch implant-supported monolithic zirconia fixed prostheses: measurements and recommendations for optimal design. J Prosthodont 2018;27:501-8.

3. Jokstad A, Shokati B. New 3D technologies applied to assess the long-term clinical effects of misfit of the full jaw fixed prosthesis on dental implants. Clin Oral Implants Res 2015; 26:1129-34.

4. de Torres EM, Rodrigues RC, de Mattos Mda G, Ribeiro RF. The effect of commercially pure titanium and alternative dental alloys on the marginal fit of one-piece cast implant frameworks. J Dent 2007;35:800-5.

5. Ciocca L, Meneghello R, Savio G, Scheda L, Monaco C, Gatto MR, Micarelli C, Baldissara P. Manufacturing of metal frameworks for full-arch dental restoration on implants: A comparison between milling and a novel hybrid technology. J Prosthodont 2019;28:556-63.

6. Abduo J, Lyons K. Effect of vertical misfit on strain within screw-retained implant titanium and zirconia frameworks. J Prosthodont Res 2012;56:102-9.

7. Burguete RL, Johns RB, King T, Patterson EA. Tightening characteristics for screwed joints in osseointegrated dental implants. J Prosthet Dent 1994;71:592-9.

8. Presotto AGC, Oliveira LV, Pisani MX, Barão VAR, Mesquita MF. Influence of spark erosion on the fit of screw-retained Co-Cr fixed complete denture frameworks veneered with different materials. J Prosthet Dent 2018;119:797-803.

9. Abduo J. Fit of CAD/CAM implant frameworks: a compre- 
hensive review. J Oral Implantol 2014;40:758-66.

10. Abduo J, Lyons K, Waddell N, Bennani V, Swain M. A comparison of fit of CNC-milled titanium and zirconia frameworks to implants. Clin Implant Dent Relat Res 2012;14:e209.

11. de França DG, Morais MH, das Neves FD, Carreiro AF, Barbosa GA. Precision fit of screw-retained implant-supported fixed dental prostheses fabricated by CAD/CAM, copymilling, and conventional methods. Int J Oral Maxillofac Implants 2017;32:507-13.

12. de França DG, Morais MH, das Neves FD, Barbosa GA. Influence of CAD/CAM on the fit accuracy of implant-supported zirconia and cobalt-chromium fixed dental prostheses. J Prosthet Dent 2015;113:22-8.

13. Beuer F, Schweiger J, Edelhoff D. Digital dentistry: an overview of recent developments for $\mathrm{CAD} / \mathrm{CAM}$ generated restorations. Br Dent J 2008;204:505-11.

14. Drago C, Howell K. Concepts for designing and fabricating metal implant frameworks for hybrid implant prostheses. J Prosthodont 2012;21:413-24.

15. Bhering CL, Marques Ida S, Takahashi JM, Barão VA, Consani RL, Mesquita MF. The effect of casting and masticatory simulation on strain and misfit of implant-supported metal frameworks. Mater Sci Eng C Mater Biol Appl 2016;62: 746-51.

16. Pieralli S, Kohal RJ, Rabel K, von Stein-Lausnitz M, Vach K, Spies BC. Clinical outcomes of partial and full-arch all-ceramic implant-supported fixed dental prostheses. A systematic review and meta-analysis. Clin Oral Implants Res 2018;29:22436.

17. Kunii J, Hotta Y, Tamaki Y, Ozawa A, Kobayashi Y, Fujishima A, Miyazaki T, Fujiwara T. Effect of sintering on the marginal and internal fit of CAD/CAM-fabricated zirconia frameworks. Dent Mater J 2007;26:820-6.

18. Abduo J, Swain M. Influence of vertical misfit of titanium and zirconia frameworks on peri-implant strain. Int J Oral Maxillofac Implants 2012;27:529-36.

19. Faucher RR, Nicholls JI. Distortion related to margin design in porcelain-fused-to-metal restorations. J Prosthet Dent 1980;43:149-55.

20. Nakaoka MM, Nuñez-Pantoja JM, Takahashi JM, Consani RL, Mesquita MF. Misfit of pure titanium frameworks: effect of veneer coverage and spark erosion process. Acta Odontol Scand 2011;69:238-42.

21. Silva TB, De Arruda Nobilo MA, Pessanha Henriques GE, Mesquita MF, Guimaraes MB. Influence of laser-welding and electroerosion on passive fit of implant-supported prosthesis. Stomatologija 2008;10:96-100.

22. Jemt T. Failures and complications in 391 consecutively inserted fixed prostheses supported by Brånemark implants in edentulous jaws: a study of treatment from the time of prosthesis placement to the first annual checkup. Int J Oral Maxillofac Implants 1991;6:270-6.

23. Farina AP, Spazzin AO, Consani RL, Mesquita MF. Screw joint stability after the application of retorque in implant-supported dentures under simulated masticatory conditions. J Prosthet Dent 2014;111:499-504.
24. Bickford JH. An Introduction to the designs and behavior of bolted joints. New York: Marcel Dekker; 1995. p. 515-64.

25. Gomes ÉA, Tiossi R, Faria AC, Rodrigues RC, Ribeiro RF. Torque loss under mechanical cycling of long-span zirconia and titanium-cemented and screw-retained implant-supported CAD/CAM frameworks. Clin Oral Implants Res 2014;25:1395402.

26. Bhering CL, Mesquita MF, Kemmoku DT, Noritomi PY, Consani RL, Barão VA. Comparison between all-on-four and all-on-six treatment concepts and framework material on stress distribution in atrophic maxilla: A prototyping guided 3D-FEA study. Mater Sci Eng C Mater Biol Appl 2016;69:71525.

27. Presotto AG, Bhering CL, Mesquita MF, Barão VA. Marginal fit and photoelastic stress analysis of CAD-CAM and overcast 3-unit implant-supported frameworks. J Prosthet Dent 2017;117:373-9.

28. Presotto AGC, Barão VAR, Bhering CLB, Mesquita MF. Dimensional precision of implant-supported frameworks fabricated by 3D printing. J Prosthet Dent 2019;122:38-45.

29. Wiskott HW, Nicholls JI, Belser UC. Stress fatigue: basic principles and prosthodontic implications. Int J Prosthodont 1995;8:105-16.

30. ISO 14801. Dentistry - Implants - Dynamic loading test for endosseous dental implants. International Standards Organization (ISO); Geneva; Switzerland, 2016. Available at: http://www.iso.org/iso/home/store/catalogue_tc/catalogue_detail.htm?csnumber $=61997$.

31. Braian M, Jönsson D, Kevci M, Wennerberg A. Geometrical accuracy of metallic objects produced with additive or subtractive manufacturing: A comparative in vitro study. Dent Mater 2018;34:978-93.

32. Abduo J, Lyons K, Bennamoun M. Trends in computer-aided manufacturing in prosthodontics: a review of the available streams. Int J Dent 2014;2014:783948.

33. Frost HM. A 2003 update of bone physiology and Wolff's Law for clinicians. Angle Orthod 2004;74:3-15.

34. Papanagiotou HP, Morgano SM, Giordano RA, Pober R. In vitro evaluation of low-temperature aging effects and finishing procedures on the flexural strength and structural stability of Y-TZP dental ceramics. J Prosthet Dent 2006;96:154-64.

35. Svanborg P, Norström Saarva V, Stenport V, Eliasson A. Fit of 3Y-TZP complete-arch implant-supported fixed dental prostheses before and after porcelain veneering. J Prosthet Dent 2019;122:137-41.

36. Skalak R. Biomechanical considerations in osseointegrated prostheses. J Prosthet Dent 1983;49:843-8.

37. Breeding LC, Dixon DL, Nelson EW, Tietge JD. Torque required to loosen single-tooth implant abutment screws before and after simulated function. Int J Prosthodont 1993;6:435-9.

38. Worni A, Kolgeci L, Rentsch-Kollar A, Katsoulis J, MericskeStern R. Zirconia-based screw-retained prostheses supported by implants: A retrospective study on technical complications and failures. Clin Implant Dent Relat Res 2015;17:1073-81. 